\title{
The Prevalence and Treatment Outcomes of Primary Tooth Injuries
}

\author{
Volkan Arikan ${ }^{a}$ \\ Saziye Saria \\ Hayriye Sonmez ${ }^{a}$
}

\begin{abstract}
Objectives: The aim of the present study was to evaluate the type and prevalence of primary tooth injuries, as well as their treatment and treatment outcomes, among children referred to the Department of Pedodontics at the Ankara University Faculty of Dentistry in Turkey.

Methods: The study population consisted of patients applying to the department with a primary tooth injury over a period of 21 months. Fifty-one patients presented with trauma to 99 primary teeth. Clinical and radiographic examinations were conducted on each patient. Age, sex, time, cause of injury, and number of teeth affected were recorded, and the type of trauma was identified according to Andreasen's classification. The teeth were treated by one of the authors.

Results: The majority of trauma occurred between the ages of 2 and 4 . The most common type of injury was lateral luxation (33.3\%). Most injuries (33.3\%) presented during May. The most common form of treatment was follow-up only (39.4\%), followed by extraction (29.3\%) and root canal treatment (12.1\%). The average follow-up period was 11 months. During the follow-up period, complications were observed in 4 teeth.

Conclusions: The study results show that in the absence of acute symptoms, parents tend not to apply to a dental clinic for children's injuries. This finding highlights the importance of informing the public about primary tooth injuries and their consequences. (Eur J Dent 2010;4:447-453)
\end{abstract}

Key words: Dental trauma; Primary teeth; Prevalence; Treatment outcomes.

ankara University, Faculty of Dentistry, Department of Pedodontics, Ankara, Turkey.

- Corresponding author:

Volkan Arikan

Ankara Universitesi, Dis Hekimligi Fakultesi

Pedodonti Ana Bilim Dali, Besevler, Ankara, 06500, Turkey.

Phone: +903122965670

Fax: +90 3122123954

E-mail: dt.volkandyahoo.com

\section{INTRODUCTION}

Dental trauma among young people represents a widespread clinical and dental public health problem. ${ }^{1}$ Among children younger than 6 , $18 \%$ of all somatic injuries affect the oral region. ${ }^{2-5}$ The prevalence of traumatic dental injuries among this age group has been reported to vary from $11 \%$ to $30 \% .^{6-9}$ In addition to causing pain, traumatic injuries to primary teeth can result in functional and 
esthetic problems ${ }^{10}$ and can affect the developing tooth germ. ${ }^{11,12}$ Despite the significance of primary tooth injuries, few studies are available on the topic, and few epidemiological studies include primary teeth. The purpose of the present study was to evaluate the type, prevalence, and treatment outcomes of primary tooth injuries among children referred to the Department of Pedodontics at the Ankara University Faculty of Dentistry in Turkey.

\section{MATERIALS AND METHODS}

The study population consisted of all patients applying to the Ankara University Faculty of Dentistry's Department of Pedodontics with a primary tooth injury over the 21-months period from 15 May 2007 to 15 February 2009. Clinical and radiographic examinations were conducted on each patient. Age, sex, time of injury, cause of injury, and number of teeth affected were recorded, and the type of trauma was identified according to Andreasen's classification, ${ }^{2}$ as follows:

1. Enamel fracture, including enamel chipping;

2. Enamel-dentin fracture, without pulpal involvement;

3. Enamel-dentin fracture, with pulpal involvement;

4. Root fracture;

5. Crown-root fracture, without pulpal involvement;

6. Crown-root fracture, with pulpal involvement;

7. Concussion;

8. Subluxation;

9. Intrusive luxation;

10. Extrusive luxation;

11. Lateral luxation;

12. Avulsion.

Examination and treatment planning were performed by two of the authors. No disagreement Table 1. Distribution of patients according to age and sex.

\begin{tabular}{l|c|c|c}
\hline Age & Girl & Boy & Total \\
\hline 1 & - & 2 & 2 \\
\hline 2 & 7 & 11 & 18 \\
\hline 3 & 6 & 4 & 10 \\
\hline 4 & 3 & 9 & 12 \\
\hline 5 & 2 & 3 & 5 \\
\hline 6 & 2 & 1 & 3 \\
\hline 7 & - & 1 & 1 \\
\hline Total & 20 & 31 & 51 \\
\hline
\end{tabular}

occurred between the examiners. A total of 99 teeth in 51 patients were treated by one of the authors (V. A.). Informed consent was obtained from the parents of all patients.

\section{RESULTS}

During the 21-months period from 15 May 2007 to 15 February 2009, 51 patients presented with trauma to 99 primary teeth. The age and sex distribution of patients is given in Table 1. Of the 51 patients, 31 were boys $(60.8 \%)$, and 20 were girls (39.2\%).

In total, 21 patients (41.2\%) presented with 1 affected tooth; 20 patients (39.2\%), with 2 affected teeth; and 10 patients (19.6\%), with 3 or more affected teeth. With the exception of 1 patient, all injuries were to the maxillary arch.

The distribution of injuries by affected tooth is shown in Table 2. The most commonly affected tooth was the maxillary left central incisor $(74.5 \%)$, followed by the maxillary right central incisor $(64.7 \%)$.

The distribution, by month, of dental injuries in patients presenting at the clinic over the first 12 months of the study is given in Table 3. Most injuries (33.3\%) presented during the month of May.

The distribution of injuries by etiology is summarized in Figure 1. The most common cause of injury was falling $(80.4 \%)$, followed by collision (11.8\%).

The distribution of injuries by patient age and injury type is shown in Table 4. Luxation injuries accounted for the majority of injuries (35/41, $85.4 \%$ ) at age 2 , whereas hard tissue injuries accounted for the majority of injuries $(12 / 22,56 \%)$ at age 4 .

The distribution of injuries by type and treatment is summarized in Table 5 . Overall, the Table 2. Distribution of injuries according to affected tooth.

\begin{tabular}{lc}
\hline No. of tooth & No. of patient \\
\hline 51 & 33 \\
61 & 38 \\
52 & 12 \\
62 & 12 \\
71 & 1 \\
72 & 1 \\
73 & 1 \\
81 & 1 \\
\hline
\end{tabular}


most common type of injury was lateral luxation (33.3\%), followed by subluxation (14.1\%). Soft tissue injuries were observed in 21 of 51 patients $(41.2 \%)$. The most common form of treatment was follow-up only (39/99, 39.4\%), followed by extraction $(29 / 99,29.3 \%)$ and root canal treatment (12/99, 12.1\%).

The majority of extracted teeth (19/29) were from patients aged 3 years and younger, with extraction required in 16 of these cases because the children's uncooperative behavior made it impossible to carry out any other treatment. Five of the 29 extracted teeth had root fractures, for which treatment is contraindicated..$^{13}$ The remainder of the extracted teeth had wide radiolucent areas around the apical region and/or pathological root resorption resulting from the delay between the time of injury and presentation at the clinic for treatment.

Of the teeth receiving no treatment but followup, $28.2 \%$ were intrusive luxations, none of which appeared to be a risk to their successors because of the direction of intrusion. All of these teeth re-erupted during the follow-up period. Another $33.3 \%$ of teeth treated by follow-up only were lateral luxations, all of which were luxated less than $2 \mathrm{~mm}$, had no occlusal interference, and were luxated in the palatinal direction, so they did not pose a risk to their successors.

Root-canal treatment was performed on 8 of the laterally luxated teeth. All of these teeth were repositioned with appropriate pressure and splinted with $0.5 \mathrm{~mm}$ orthodontic wire and composite resin. The splint time was 10 days for all teeth, with the exception of one case in which the splint time was increased to 14 days due to tooth mobility. All teeth receiving root canal treatment were followed up for a minimum of 1 year and,

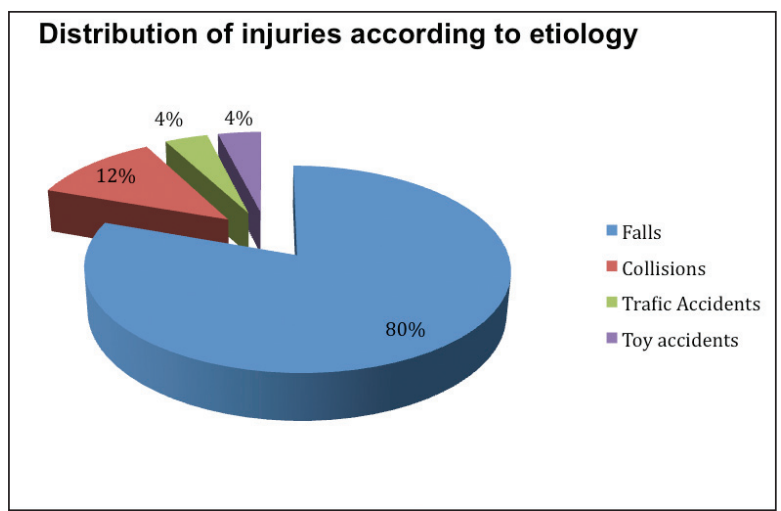

Figure 1. Distribution of injuries according to etiology. with the exception of one case, were judged to be clinically and radiographically successful.

No treatment but follow-up was applied to avulsed teeth, with the exception of one case in which a patient aged 3 years presented at the clinic 20 min after the time of injury. The tooth had been stored in milk since the injury, and the injury had occurred inside the home, so the risk of contamination was considered minimal. Given the circumstances, the decision was made to reimplant the tooth after obtaining informed consent from the parents.

The average follow-up period was 11 months, with the longest being 21 months and the shortest 3 months. All cases followed up with for less than 6 months were extractions, and, with the exception of 1 re-implantation, all cases for which follow-up lasted from 6 months to 1 year were cases receiving no treatment but follow-up.

Table 5 also presents the complications observed during follow-up. Complications were observed during follow-up in 4 cases. In one of these cases, a tooth in a 2 years old patient was intruded $4 \mathrm{~mm}$. Although the tooth re-erupted completely, pathological external root resorption was observed at 3 weeks following the injury, and the patient's age made it impossible to obtain cooperation; therefore, the tooth had to be extracted. In another case with complications during follow-up, a laterally luxated central incisor in a patient who applied to the clinic 1 day after injury was gently repositioned, and a semi-rigid splint constructed of $0.5 \mathrm{~mm}$ orthodontic wire and composite resin was applied. The splint was removed after 1 week, and a root canal was performed using calcium hydroxide paste. After 9 months, the tooth had to be extracted due to pathological root resorption that had started in the $7^{\text {th }}$ month. Complications during follow-up also occurred in a patient with 2 crown fractures with pulpal involvement that received root canal treatment. After 7 months of follow-up, the teeth were again exposed to serious crown trauma that made restoration impossible; therefore, these teeth were also extracted.

Only 16 of the 51 patients (31.4\%) presented at our clinic within 24 hours of injury, whereas 17 (33.3\%) presented between 24 hours and 10 days following injury and $18(35.3 \%)$ presented after 10 days. 


\section{DISCUSSION}

The results of the present study generally conform to those of previous studies in the literature. Almost all studies report a higher frequency of dental trauma among boys than girls., 14-18 In our study, boys were found to be 1.5 times more likely to receive a dental injury than girls. This higher incidence may be associated with differences in the types of games played by boys and girls.

During the period when children start to walk, especially between the ages of 1 and 2 years, poor muscle coordination results in an increased risk of trauma. $4,6,19$ Andreasen reported another peak in injury at age 4, when children's physical activity increases. ${ }^{2}$ In line with previous studies, our study found that $39.2 \%$ of traumatic injuries occurred between the ages of 1 and 2 and $23.5 \%$ at age 4 . These findings highlight the need to inform parents and preschool teachers about traumatic injuries, since nearly all of the injuries at these ages occur at home or at preschool.

The majority of patients had more than 1 tooth injured by trauma (58.8\%). This finding stands in contrast to previous findings that show the majority of traumatic injury involves only 1 injured tooth. In a retrospective study of 543 children with trau-

Table 3. Distribution of dental injuries according to the month presented at our clinic in the first 12 months.

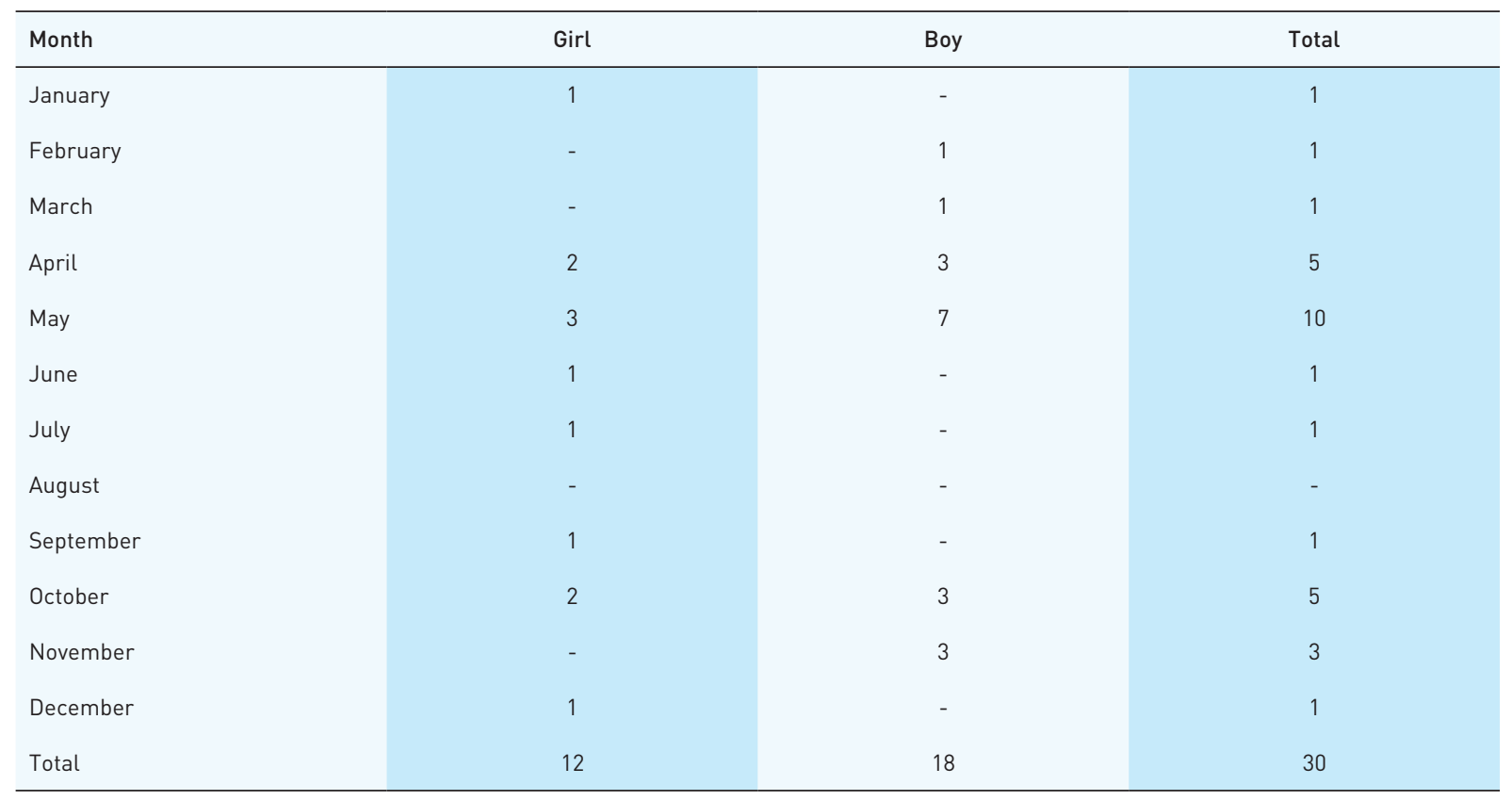

Table 4. Distribution of injuries by patient age and injury type.

\begin{tabular}{|c|c|c|c|c|c|c|c|c|}
\hline & 1 & 2 & 3 & 4 & 5 & 6 & 7 & Tota \\
\hline Fracture of enamel & - & - & - & 1 & - & - & - & 1 \\
\hline $\begin{array}{l}\text { Fracture of enamel-dentin with } \\
\text { pulpal involvement }\end{array}$ & - & 3 & 5 & 5 & - & - & - & 13 \\
\hline Crown-root fracture with pulpal involvement & - & - & - & 2 & - & - & - & 2 \\
\hline Subluxation & - & 4 & 4 & 1 & 5 & - & - & 14 \\
\hline Intrusive luxation & 1 & 9 & 1 & - & - & - & - & 11 \\
\hline Avulsion & 2 & 7 & 1 & 1 & 1 & - & - & 12 \\
\hline TOTAL & 4 & 41 & 17 & 22 & 9 & 4 & 2 & 99 \\
\hline
\end{tabular}


matic injuries, Rodriguez reported that $70.9 \%$ had only 1 injured tooth; ${ }^{1}$ Skaare and Jacobsen also reported a higher percentage of patients (58\%) with only 1 injured tooth, ${ }^{15}$ as did Oliviera et al. ${ }^{16}$ Differences in methodologies and sample sizes may account for the variation in the numbers of injured teeth reported by different studies.

In the present study, except for 1 tooth, all of the teeth affected by traumatic injuries were in the maxillary arch. In line with previous studies, 1,14-16 the maxillary central incisors were found to be the most frequently injured teeth. This is probably related to the position of the maxillary central incisors, which exposes them to direct traumatic force. In contrast to the mandible, whose mobility tends to reduce the impact of force, the maxillary bone's fixed position in the skull prevents it from absorbing traumatic force, and, thus, the maxillary teeth are directly affected. ${ }^{20}$

Our study found that most traumatic injuries to primary teeth $(33.3 \%$ ) presented in the month of May. This result is in agreement with Saroglu and Sonmez ${ }^{14}$ and Perez et al, ${ }^{21}$ which indicates a seasonal variation in the distribution of traumatic injuries. This variation may be due to a sudden increase in children's physical activity as temperatures increase in the springtime.

In terms of etiology, our study found falls to be the most common cause of traumatic injury to primary dentition $(80.4 \%)$. This is in line with ear- lier findings $\mathrm{s}^{14,15,22}$ and, as mentioned above, may be related to children's lack of muscle coordination during early childhood. The next most frequent cause of traumatic injury to primary dentition $(11.8 \%)$ was collisions.

Luxation was the most common type of injury (46.5\%). This finding is in line with most previous studies, 6,14,23,24 although some authors have found hard tissue injuries to be the most common type of injury to primary dentition. ${ }^{7,25}$ The more frequent occurrence of periodontal tissue injury may be explained by the more resilient character of bone in young children in comparison to young adults. In our study, the rate of hard tissue injuries increased with age, whereas the rate of luxation injuries decreased (Table 4). Although some exceptions were observed after age 4 , the number of cases is insufficient to be conclusive.

The most common treatment for injured primary teeth was follow-up only (39.4\%). Extraction was the second most common (29.3\%). This finding is similar to that of previous studies. ${ }^{21,26,28}$

According to 2007 guidelines for traumatic injuries, ${ }^{13}$ follow-up for re-eruption is recommended for intruded primary teeth if the apex is displaced through or toward the labial bone plate. All the teeth with intrusive luxations in the present study met these criteria, and all re-erupted during follow-up periods of between 3 weeks and 2 months. However, in one of these cases, patholog-

Table 5. Distribution of injuries by type and treatment applied, along with complications that occurred during follow-up.

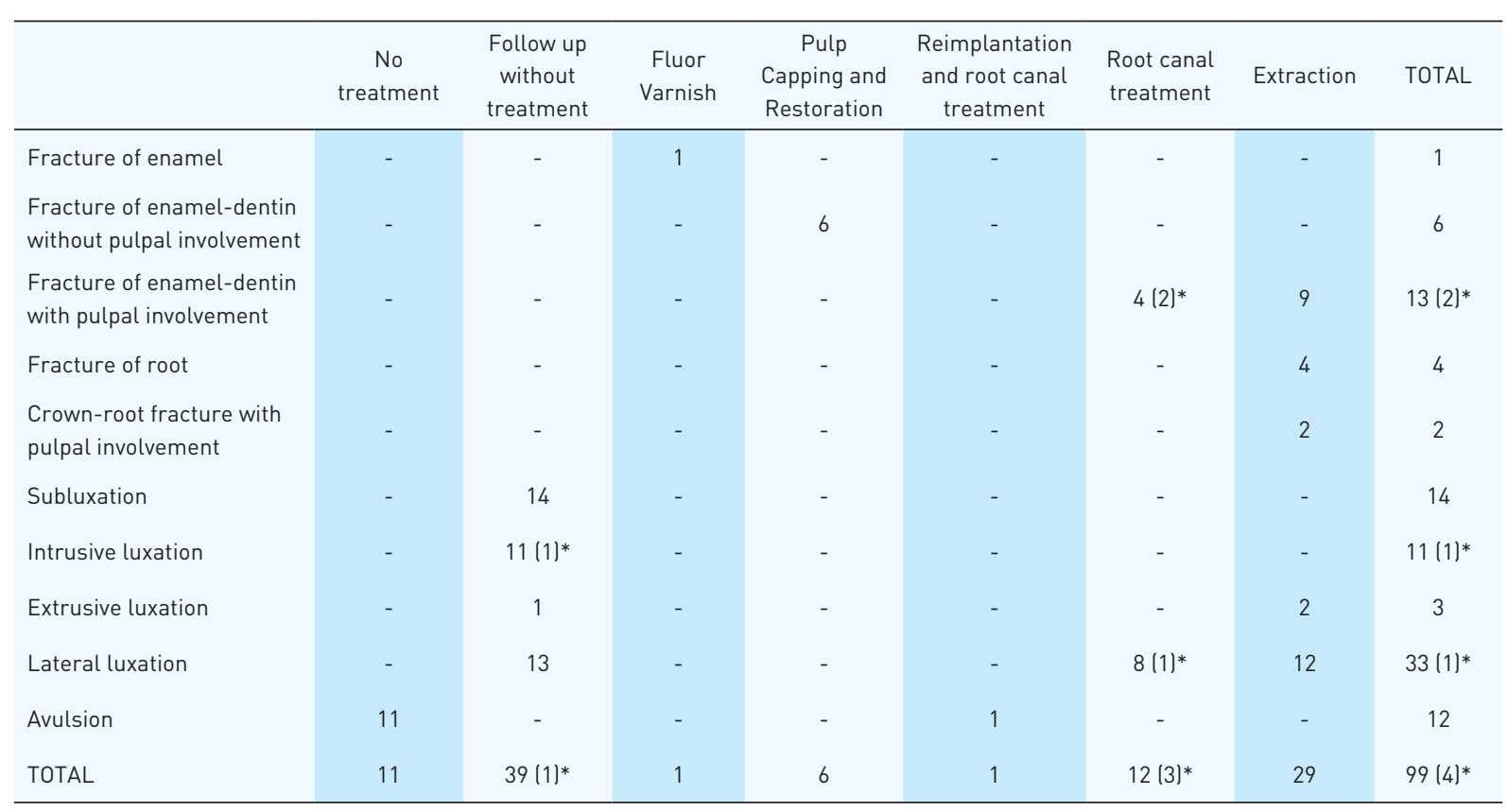

*: Teeth that had complications during their follow-up period. 
ical root resorption was observed. This tooth had intruded $4 \mathrm{~mm}$ into the alveolar bone, compared to intrusion of less than $3 \mathrm{~mm}$ for all the other teeth. In view of this finding, one might conclude that the prognosis for intruded primary teeth is dependent upon the degree of intrusion, with teeth intruded less than $3 \mathrm{~mm}$ capable of spontaneous re-eruption and healing without any treatment.

Although guidelines do not recommend reimplanting primary teeth, ${ }^{13}$ some authors have reported successful cases of reimplantation. ${ }^{29,30}$ In deciding whether to attempt reimplantation, the benefits as well as risks to the patient should be weighed carefully, and the tooth should be followed up with closely. In our case, reimplantation was considered appropriate because of the short time between injury and presentation and the fact that the tooth had been stored in milk following injury. Additionally, a close follow-up of the patient was possible. At 7 months of follow-up, both clinical and radiographic examination indicated the treatment to be successful, and close follow-up is continuing.

Several recent studies have been conducted on the prevalence of dental trauma among children in Ankara, Turkey. A study by Saroglu and Sonmez ${ }^{14}$ examining dental trauma to both primary and permanent dentition among children presenting at the Ankara University Faculty of Dentistry's Department of Pedodontics described 34 cases of traumatic primary tooth injury treated during an 18 months period 1999 October to 2001 April). Another prevalence study by Altay and Gungor ${ }^{26}$ conducted at Hacettepe University, a university dental clinic in Ankara, described 72 cases of traumatic injury to primary teeth treated over a 4 years period (1996-2000). One can conclude from these studies and the present study that the incidence of traumatic injury to primary dentition in Ankara has increased in recent years. It is also possible that the increase in patients presenting with traumatic injury to a primary tooth may be related to changes in government health policy and increases in the number of patients applying to university hospitals instead of other private or state hospitals.

\section{CONCLUSIONS}

Findings from the present study indicate that in the absence of acute symptoms, parents tend not to apply to a dental clinic for children's dental injuries, especially those affecting primary teeth. However, the finding of periapical radiolucency among $39.1 \%$ of patients who did not apply to a clinic until at least 10 days after injury highlights the importance of immediate examination and treatment of traumatic injuries to primary teeth. This finding also indicates the importance of informing the public, especially parents and teachers, about primary tooth injuries and their consequences.

\section{REFERENCES}

1. Rodriguez JG. Traumatic anterior dental injuries in Cuban preschool children. Dent Traumatol 2007;23:241-242.

2. Andreasen JO, Andreasen FM, Andersson L. Textbook and color atlas of traumatic injuries to the teeth, 4 th edn. Oxford: Blackwell Munksgaard; 2007.

3. Petersson EE, Andersson L, Sorensen S. Traumatic oral vs. non-oral injuries. Swed Dent J 1997;21:55-68.

4. Glendor $U$, Andersson L. Public health aspects of oral diseases and disorders: dental trauma. In: Pine C, Harris R, editors. Community oral health. Quintessence publishing London; 203-214, 2007

5. Glendor U, Halling A, Andersson L, Eilert-Peterson E. Incidence of traumatic tooth injuries in children and adolecents in the country of Vastmanland, Sweden. Swed Dent J 1996;20:15-28.

6. Cunha RF, Pugliesi DM, Mello Vieira AE. Oral trauma in Brazilian patients aged 0-3 years. Dent Traumatol 2001;17:210212

7. Hargreaves JA, Cleaton Jones PE, Roberts GJ, Williams S, Matejka JM. Trauma to primary teeth of South African preschool children. Endod Dent Traumatol 1999;15:73-76.

8. Bijella MF, Yared FN, Bijella VT, Lopes ES. Occurrence of primary incisor traumatism in Brazilian children: a houseby-house survey. ASDCJ Dent Child 1990;57:424-427.

9. Forsberg CM, Tedestam G. Traumatic injuries to teeth in Swedish children living in an urban area. Swed Dent $J$ 1990;14:115-122.

10. Rajab LD. Traumatic dental injuries in children presenting for treatment at the Department of Pediatric Dentistry, Faculty of Dentistry, University of Jordan, 1997-2000. Dent Traumatol 2003;19:6-11.

11. Diab M, elBadrawy HE. Intrusion injuries of primary incisors. Part III. Effects on the permanent successors. Quintessence Int 2000;31:377-384.

12. Tarjan J, Balaton P, Keri I. Consequence and therapy of primary tooth intrusion. J Int Assoc Dent Child 1988;19:25-28. 
13. Flores MT, Malmgren B, Andersson L, Andreasen JO, Bakland LK, Barnett F, Bourguignn C, Diangelis A, Hicks L, Sigurdsson A, Trope M, Tsukiboshi M, von Arx T. Guidelines for the management of traumatic dental injuries. III. Primary teeth. Dental Traumatol 2007;23:196-202.

14. Saroḡlu I, Sönmez H. The prevalence of traumatic injuries treated in the pedodontic clinic of Ankara University, Turkey, during 18 months. Dent Traumatol 2002;18:299-303.

15. Skaare AB, Jacobsen I. Primary tooth injuries in Norwegian children (1-8 years). Dent Traumatol 2005;21:315-319.

16. Oliviera LB, Marcenes W, Ardenghi TM, Sheiham A, Bönecker M. Traumatic dental injuries and associated factors among Brazilian preschool children. Dent Traumatol 2007;23:76-81.

17. Onetto JE, Flores MT, Garbarino ML. Dental trauma in children and adolescents in Valparaiso, Chile. Endod Dent Traumatol 1994;10:223-227.

18. Kargul B, Caḡlar E, Tanboga I. Dental trauma in Turkish children, Istanbul. Dent Traumatol 2003;19:72-75.

19. Llarena del Rosario ME, Acosta AV, Garcia-Godoy F. Traumatic injuries to primary teeth in Mexico City children. Endod Dent Traumatol 1992;8:213-214.

20. Baghdady VS, Ghose LJ, Enke H. Traumatic anterior teeth in Iraqi and Sudanese children- a comparative study. J Dent Res 1981;60:677-680.

21. Perez R, Berkowitz R, Mcllveen L, Forrester D. Dental trauma in children: a survey. Endod Dent Traumatol 1991;7:212213.

22. Battenhouse MR, Nazif MM, Zullo T. Emergency care in pediatric dentistry. J Dent Child 1988;55:68-71.

23. Andreasen JO, Ravn JJ. Epidemiology of traumatic dental injuries to primary and permanent teeth in a Danish population sample. Int J Oral Surg 1972;1:235-239.

24. Caldas AF Jr, Burgos ME. A Retrospective study of traumatic dental injuries in a Brazilian dental trauma clinic. Dental Traumatol 2001;17:250-253.

25. Kramer PF, Zembruski C, Ferreira SH, Feldens CA. Traumatic dental injuries in Brazilian preschool children. Dent Traumatol 2003;19:299-303.

26. Altay N, Gungor HC. A retrospective study of dento-alveolar injuries of children in Ankara, Turkey. Dent Traumatol $2001 ; 17: 201-204$

27. Sandalli N, Cildir S, Guler N. Clinical investigation of traumatic injuies in Yeditepe University, Turkey during the last 3 years. Dent Traumatol 2005;21:188-194.

28. De Carvalho Rocha MJ, Cardoso M. Reimplantation of primary tooth--case report. Dent Traumatol 2008;24:e4-e10.

29. Boer FA, Percinoto C, Ferelle A, Cunha RF. Immediate reimplantation of primary teeth: a histological study in dogs. Dent Traumatol 2008;24:337-342. 